\title{
Hakan DEĞİRMENCİ, Türk Romanında Fetih ve Fatih, Akçağ Yayınları, Ankara, 2021, 260 s.
}

\author{
Bahar AKÇADAĞ $\breve{G}^{*}$
}

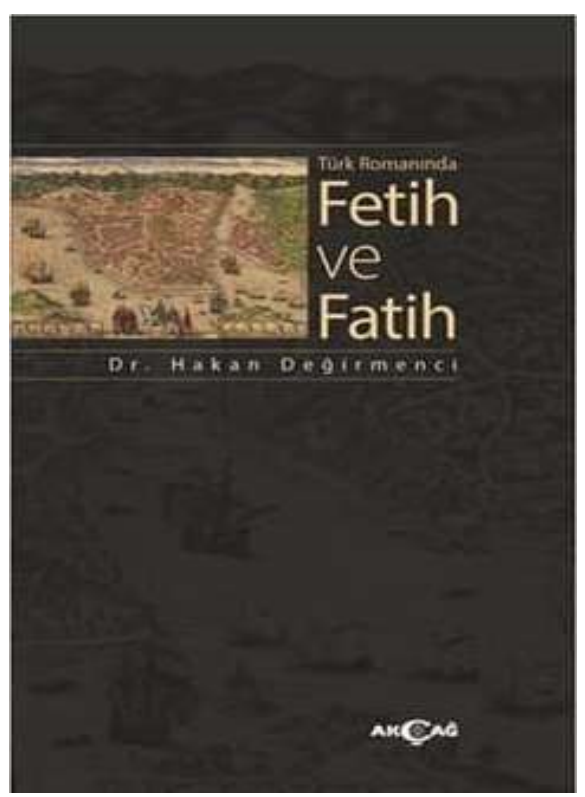

Hakan Değirmenci'nin Türk Romanında Fetih ve Fatih kitabı 2021 yılında Akçağ Yayınlarından basılmıştır. Eser Türk edebiyatında tarihi roman olarak sinıflandırılan 53 romanı kapsar. 260 sayfadan ibaret olan kitabın ana fikri, nesnel bir tarihle bağlantılı olarak kaleme alınmış edebi değer taşıyan, tarihin gerçeklerinin yanında sanatsal ve kurgusal değerleri olan romanların sıralı bir biçimde ele alınışıdır. İncelenen romanlar ana hatlarıyla tarihsel gerçeklikten hareketle kurgulanmış bir yapıdadırlar. Değirmenci kitabın giriş bölümünde tarih ve edebiyat eserinin bağlantılı konulara sahip olduğunu ancak, her ikisinin de kesin çizgilerle birbirinden ayrıldığını hassasiyetle belirtir. "...tarihi romanın tarih ile edebiyat arasında bir yerlerde, ama daha çok öncelikle bir sanat eseri olduğu yönündeki bu yaklaşım, bizim çalışmamızın da hareket noktasını oluşturacaktır." (Değirmenci, 2021: 17) ifadeleri ile kitabın muhataplarının bu ayrımın farkında olarak okuması gerektiğinin altını çizer.

Barındırdı̆̆ı ayrıntılara rağmen eser, alanla ilgili olmayan okuyucuların da dikkatini cezbedecek derecede sıralı ve temiz bir düzenle kaleme alınmıştır. Yazar dili etkili ve cümle yapısına uygun olarak kullanır. Desteklediği ve tespit ettiği fikirleri en kısa ve öz bir biçimde, dolaysız olarak ortaya koyar. Bunun yanında "Tablo" başlığı altında anlatımıyla bağlantılı olarak geniş içerikli bir tablodan faydalanmıştır. Değirmenci'nin kullandığı tablo, incelediği romanları tarihsel açıdan, olumlu ve olumsuz oluşları konusunda sinıflandırmaktadır. Tablonun tarihi 1875 'te yazılan, İstanbul'un fethi ile parçalar barındıran Hüseyin Fellah romanı ile başlatılıp 2013'te Bir Ístanbul Rüyası romanı ile sonlandırılır. Yer verilen tablonun kullanımı gerekli olmasa da bir sinıflandırma yapabilmek ve genel bir çerçeve çizebilmek adına uygun düşmüştür.

Kitapta birçok imla ve yazım hatası bulunmaktadır. Sıklıkla karşılaşılan yazım hataları, kelimelerin eksik veya yanlış yazılmasından kaynaklıdır. Yazım hataları,

\footnotetext{
* Yüksek lisans öğrencisi, Kırşehir Ahi Evran Üniversitesi, Sosyal Bilimler Enstitüsü, Türk Dili ve Edebiyatı Ana Bilim Dalı, e-posta: akcadagbahar@gmail.com ORCID: 0000-00012345-6789
} 
eserin bir doktora tezi olması nedeniyle yazarın editöryal bir okuma yaptırmamış ve kendisinin de dikkatli bir şekilde gözden geçirmemiş olmasına bağlanabilir.

Kitabın genelinde Türk romanında İstanbul'un fethinin nasıl işlendiğine odaklanılır. Ele alınan konunun kapsamı oldukça geniştir. Değirmenci tüm detayları göz önünde bulundurarak araştırmasını sonuçlandırmıştır. Kitap, vadettiği üzere Türk romanında İstanbul'un fethi ve fethin sahibi Fatih Sultan Mehmet ile ilgili olarak romanları kapsar. Yazar bu eserle Türk edebiyatında sıkça temas edilen konulardan biri ile ilgili toplu bir kaynak sunar ve tarihi roman türünü konu çerçevesinde bütünlüklü bir halde ele alarak, fetih meselesinin kurgusal alandaki iz düşümünü ortaya koyar.

Yazar kitabını kaleme alırken, başlıklar ve başlıkların içeriğine dikkatle yaklaşmıştır. Üç ana bölümden oluşan kitapta, konuyu kronolojik bir düzende verebilmek adına alt başlıklara epeyce yer verilmiştir. Alt başlıklar altında değindiği konular alıntılarla zenginleştirilmiş net bir şekilde açıklanmış olduğu için doyurucudur. Kaynak kullanımı bakımından kitap oldukça zengin içeriklidir. Araştırmaya dahil olan 53 romanın dışında alan ile ilgili olarak, ulaşılabilecek neredeyse bütün kaynaklara temas edilmiştir. Bu kaynakların kullanımında yazar hem tarihi romanlarla ilgili akademik kitaplara ulaşmış hem de İstanbul'un fethi ile ilgili yazılmış akademik kitaplara ulaşmıştır

Kitap, "Sunuş, "Kısaltmalar", Giriş, Sonuç, "Kaynaklar" ve "Tablo" bölümleri dışında üç ana bölüm ve başlıktan oluşur. Yazar "Giriş" kısmında tarih ile edebiyat arasındaki ilişkiye kısaca değinir. Tarih ve romanın birbirinden ayrı değerlendirilmesi gerektiği konusunu vurgulayan yazar, tarihi romanın neliğini ve nasıl olması gerektiğini irdeler. Değerlendirmeler yapılırken sadece Türk romanı örnek gösterilmez ve genel bir çerçeve çizilerek diğer edebiyatlardaki tarihi romanlar da işin içine dahil edilir. Yazar bu konu hakkındaki görüşlerini desteklemek için yerli ve yabancı birçok araştırmacının adını zikreder ve bahsi geçen araştırmacıların fikirlerine de alıntı yöntemiyle yer verir. Giriş bölümünde oldukça geniş bir kaynak kullanımı vardır.

Birinci bölüm olan "Fetih Öncesi Osmanlı ve Bizans-Hristiyan Dünyası" ana başlığı kendi içerisinde sınıflara ayrılır ve "Fetih Öncesi Osmanlı Devleti" birinci bölümün ilk alt başlığıdır. Bu başlık genel olarak, siyasi durum, halkın savaş karşısındaki tavrı, sosyo-kültürel dinamikler olmak üzere ayrı başlıklarda değerlendirilir. Osmanlı Devleti'nin fetihten önceki siyasi durumu, incelenen romanların tamamında, şehzadenin tahta çıkar çıkmaz aktif bir şekilde dış ilişkileri düzenlemeye giriştiğini işaret eder. "Ele aldığımız romanlarda, fetih öncesi siyasi ilişkiler bağlamında Karaman tehlikesinden çok, Bizans'la ilişkiler üzerinde daha çok durulmuş, fethe odakl bir uluslararası ilişkiler ăğ öne çıkarılmıştır."'( Değirmenci 2021: 23) Rum Ateşi (1966), Sultan'l Öldürmek (2012), Fatih Sultan Mehmet (2013), Hocaefendi'nin Sandukası (1999), Dünyanın İlk Günü (2012), Fatih-1453 (2010) romanları fethin alt yapısını oluşturmak amacıyla ilk etapta Fatih Sultan Mehmet'in İstanbul'u neden istediği bağlamında 
değerlendirilir Romanlardan hareketle bu sebepler, ekonomik, jeopolitik, psikolojik ve şahsi nedenlerdir. Detaylandırmak gerekirse Fatih'in nedenleri; devletin bekasını sağlamak, ilk tahta çıkış deneyiminden sonra kendini ispatlamak ve İstanbul'u hayalini kurduğu üzere dünya şehri yapmaktır. Başlığa bağlı kalınarak "siyasi durum" anlatılır.

Halkın fetih karşısındaki tavrı, romanlar bağlamında olumlu olarak karşımıza çıkar. Halk bu romanlarda heyecanlı, istekli, coşkulu ve mutludur. Sosyoekonomik yap1, adalet sistemi, Osmanlı toplumunun mert, vicdanlı, dayanışma halinde oluşu, ilme düşkünlüğü, hoşgörülü oluşu "Sosyo-kültürel Dinamikler" alt başlığında değerlendirilir. Osmanlı'nın fetih için madden ve manen hazır olduğu Fatih Feneri (1952), Istanbul Düşserken (2008), Tarihin Dönüm Noktası: Fatih Sultan Mehmet (2007), Müjdelenen Komutan: Fatih Sultan Mehmet (2012), Dünyanın İlk Günü, Kuşatma-1453 (2009) romanlarının özellikle kesiştiği noktalardandır. Osmanlı penceresinden değerlendirilen romanlar bir de "Fetih Öncesi Bizans-Hristiyan Dünyası" penceresinden değerlendirilir.

Bizans'ın siyasi ve genel durumu Osmanlı Devleti'nin tam zıddıdır. Halkın ve devlet erkânının durumu genel itibarı ile iç karartıcı ve tedirgindir. Hem devlet hem de halk, fetih hazırlıklarına psikolojik olarak hazır gibidir. İstanbul'un fetih öncesi durumu, fethin zorluğu özellikle romanlarda incelenen başka bir konudur. Yaklaşan savaş için devlet erkânı ve halkın uyumlu bir birliktelik halinde olmayışı romanların hemen hepsinde gözetilir. Fethe olumlu yaklaşan romanlar özellikle Bizans halkında millî bir bilincin olmadığına işaret eder. Ayrıca bu durumun Konstantiniye'nin daha önce de defalarca kuşatılmış ancak, alınamamış oluşu ile de ilgilidir.

Romanlarda Bizans'ın sosyo-ekonomik durumu Osmanlı ile kıyaslandığında hiç de iç açıcı işlenmemiştir. "Romanlara göre dilenciler, aç insanlar, uyuz sokak hayvanları, bakımsız surları ve yer yer dökülen yapılarıyla Konstantin, ă̆ır ăğr yaklaşmakta olan ölümü bekleyen bir canlı gibidir." (Değirmenci 2021: 36) romanlardaki bu sefalet tasvirleri, fethe olumlu yaklaşan 1453 (2008), Aziz Sofi (1976), Fatih Feneri, İstanbul'u Nasıl Aldık? (1931), Tarihin Dönüm Noktası: Fatih Sultan Mehmet, Kara Büyülü Uyku (1999) romanlarında fethin bir kurtarıcı gibi görülmesine yol açacaktır. Ek olarak, Bizans'ın devlet recali, inanılmaz bir şatafat ve lüks içinde yaşarken halkın durumuna hiç ehemmiyet vermez. $\mathrm{Bu}$ durumda aranan taze kanın fetihte olacağını düşündürür.

Fetihten önce Bizans'ın ahlaki yapısı, adaletsizlikle beraber hepten bozulmuştur. Gece Vaktinde Gündömümü (1980), Süleyman Müslî (1877), Hüseyin Fellah (1875), Kara Davut (1930), Rum Ateşi, Bizans Ylkılıyor (1972) romanları bu ahlaksızlıkları tasavvur edemeyecek kadar derin işler. Şehir fakirlikten harap, adım başı fuhuş yuvası, tacizciler, tecavüzcüler, hırsızlar, eşcinsellerle dolu, güçlünün zayıfı ezdiği bir yer olarak tasvir edilir. Romanlarda saray çevresi, bu ahlaksızlıkların ve çöküşün adeta merkezi konumunda işlenmiştir. Halkın berbat yaşayışı bir yana, saray da ahlaksızlığın doruğundadır. Aşırıya kaçan eğlenceler, 
kadınlarla yapılan âlemler, kumar, saray entrikaları, aile kurumunun tamamen bozulası biraz da saraydan kaynaklanan bir durumdur.

"Yaşanan Tehlikelere Karşı Bizans Halkının Tavrı" başlığında Değirmenci'nin değindiği ve tespit ettiği konu, Bizans halkının iki türlü tavır sergilemesidir. Fatih Sultan Mehmet, İstanbul Düşerken, Güneşin Imparatoru Fatih (2012), Fatih Istanbul Kapılarinda (1953) gibi bazı romanlarda saray ve halk umarsizca eğlencelere devam ederken, Bizans 'ta Kayı Zaman (1998), Fatih Feneri gibi bazı romanlarda bıkmış, tedirgin, umutsuz, korku içinde bekleyen bir halk ve saray karşımıza çıkar. Halk da saray da artık yapacak pek bir şeyin olmadığının farkındadır ve fethin gerçekleşmemesini sağlayacak bir çözüm yolu bulunamadığından çareyi hurafelere sığınmakta bulurlar.

“Fethi Müjdeleyen Unsurlar"da geniş çaplı bir inceleme söz konusudur. Osmanlı Devleti tarafından fetihten önce kuşatmanın başarıyla sonuçlanacağına dair inanışlar bu başlıkta yer alır. Bu konulardan hemen hepsi, fethin gerçekleşeceği doğrultusunda umut vericidir. Öncelikle Kuşatma-1453, Fatih İstanbul Kapılarında, Müjdelenen Komutan: Fatih Sultan Mehmet, romanlar1 Fatih Sultan Mehmet'in doğumu sirasında gerçekleşen olağanüstü hadiselerin, onun iyi bir asker ve hayırlı bir evlat olacağı yönündedir. Bu hadiselerin başlıcaları, Fatih doğduğunda babası 2. Murat Fetih Suresi'ni okur, doğum günü Miraç Kandili'ne tekabül eder, güneş tutulması gerçekleşir. Fetih içinse, Kur'an'da geçen İstanbul'un fethi ile ilgili ayet, Eyüp Sultan'ın mezarının bulunması, yıldız kayması, deniz feneri, Madalyon, Fatih'in kokladığı kırmız gül hep fethi müjdeler. Değirmenci bu fetih müjdelerini bazen aynı kitapta birkaçı olmak üzere, bazen de ayr1 ayrı tespit ettiğini belirtir. Fethin müjdesi Fetih-1453, Boğazkesen (1995), Güneșin Imparatoru Fatih, Dünyanın İlk Günü, Fatih 1453, İstanbul'un Fethi (1954), Fatih Istanbul Kapılarında, Kara Büyülü Uyku romanlarında ise rüyalarda gizlidir. 2. Murad'ın, Akşemseddin'in, Fatih'in rüyaları da fetih girişiminin olumlu sonuçlanacağı üzerinedir. Bu rüyalar Fatih'e de askerlere de motivasyon kaynağı olur. Rüya bahsinde, Bizans tarafında da Fethin başarılı sonuçlanacağına dair rüyalara rastlanmıştır. Ayrıca Bizans'ta, yaklaşan tehlikeleri işaret eden en meşhur hadise, şehri koruduğuna inanılan Meryem Ana tasvirinin parçalanmasıdır. Yaşanan paniği anlatmak için Değirmenci: “Çı̆̆llklar, ağlamalar, dualar iniltiler birbirine karışır. Bu hal büyük bir bozguna ve paniğe sebep olur. Demek ki, Meryem şehri himaye etmekten vazgeçmiştir." (Değirmenci 2021: 63) ifadelerini kullanır.

Kitabın ikinci bölümü olan "Fetih" bölümü de tıpkı birinci bölümde olduğu gibi alt başlıklarla detaylandırılmıştır. "Fethin Teknik Hazırlıkları'nın başında Rumeli Hisarı'nın inşasına yer verilir. Değirmenci'nin bu başlıkta asıl vermek istediği, Fatih Sultan Mehmet'in fethin planı üzerine ne kadar yoğunlaştı̆̆ıdır. Denizler Delisi (1969), Boğazkesen, Fetih Sancaklart (2010), Kara Davut, Rum Ateşi, Fatih Istanbul Kapılarında, Konstantiniye'nin Yitik Günceleri (1999), Bizans'ın Son Günleri (1930), Fatih Feneri, Sultan'ı Öldürmek, Bizanslı Aspasya (1960), 
Korkusuz Cengaver (1985) romanları bu bağlamda, Rumeli Hisarı'nın inşa edilmesi, Urban Usta ve topların dökümü, Bizans surlarının aşılmazlığı karşısında Osmanlı'nın zekâsı ve denizcilik yönündeki eksiklerin giderilmesi üzerinde durur. Taranan romanların hemen hepsi bu faaliyetleri ihtiva eder.

“Askeri Hazırlıklar”da Fatih Sultan Mehmet'in öne çıkan dış antlaşmaları ve fethin olumsuz etkilenmemesi için dış tehlikelere karşı ülkeyi sağlamlaştırma gayretinin bahsi tespit edilir. İç mesele olarak da Yeniçeri Ocağı hizaya sokulur. Bunun yanında, Osmanlı'nın asker sayısı, Bizans tarafindan haberdar olabilmek adına olağanüstü titizliklerle kurulan istihbarat teşkilatı, şehrin krokisinin çıkarılması, olası herhangi bir olumsuzluğa karşı kurulan sağlık teşkilatı, Bizans surlarının dışında kalan Bizans köylerinin alınması, ordu yapılanması, askerlerin fethe dügün havasında gidecek kadar motive edilmeleri, askerleri yüreklendirmek için çalınan cenk havaları, tekbir sesleri Osmanlı'nın hazırlıklarından bahseden romanlarla tespit edilir.

"Fethin Motivasyonu”nun asıl kaynağının din birliği olduğu su yüzüne çıkarılır. Halkın da Fatih'in de askerlerin de en büyük motivasyon kaynağı, maneviyattır. Fatih özellikle Fatih Feneri, Fatih Istanbul Kapılarında, romanlarında askerlerle namaza durur, bazı romanlarda askerlerle fetihten önceki gün oruç tutulur, bazı romanlarda tepelerden ezan sesleri duyulur. Askerler de Fatih de Eyyüp El Ensari'nin ve Hz. Muhammed'in şefaatine nail olabilmek için yüreklenir. Fatih Istanbul Kapılarında ve Boğazkesen romanlarında Hacı Bektaş-1 Veli'nin kerameti de fethe işaret eder. Osmanlı tarafinın motivasyonu had safhadayken Bizans tarafında durum tam zıddıdır. Dinin birleştirici gücünün yanında bir de milli bilinç ve Türklük bilinci ön plana çıkan konulardan biridir. Tüm bu olumlu motivasyon kaynaklarının yanında Kara Davut, Bizanslı Beyaz Güvercin (1964), Istanbul Düşerken ve Fatih İstanbul Kapılarında romanlarda zalimlik, iktidar ve para hırsı, gövde gösterisi, şehvet ve ihtirasa rastlanmıştır. Bu tarz olumsuz motivasyon kaynaklarının hem Fatih'in hem de askerlerin iştahını kabarttığı işlenmiştir.

Bizans, yaklaşan Osmanlı tehlikesinin farkına geç de olsa varır ve Osmanlı gibi Bizans da birtakım savaş hazırlıkları yapmaya koyulur. Bizans ilk zamanlar Osmanlı'nın fetih girişimine pek ihtimal vermez. Bunun sebebi şehri koruyan surlara aşırı güvenmeleridir. İyiden iyiye durumun ciddiyeti kavranınca Bizans, öncelikli olarak surların dışında kalan halkların yaşadığı bölgeleri tahliye işine koyulur. Aşılması imkânsız addedilen surlar sağlamlaştırılmaya çalışılır, surların önlerine hendekler kazılır. Bizans, hali hazırda asker bulundurmadığından halktan eli silah tutanları toplar ve eğitimlere başlar. Şehirde sapan gibi ilkel aletlere bile el konulur. Ambarlara altı ay yetecek kadar erzak stoklanır. Bizans dostu bazı devletler yanlarında askerler ve savaş malzemeleri getirerek destekte bulunmaya çalışır. Romanlarda üç aşağı beş yukarı asker sayısı, sekiz bindir ve yirmi iki kilometre surları sekiz bin asker koruyacaktır. Savaşın her iki tarafı da surların zayıf noktalarını tespit ederek o noktalarda yoğunlaşmışlardır. 
Fethin "Diğer Hadiseleri" romanlarda Osmanlı tarafindan inanılmaz bir motivasyonla anlatılır. Bizans tarafi da zıt bir şekilde kararsız ve tedirgindir. Olacaklardan haberdar olmak için Osmanlı'ya casus gönderir ve casusun aktardığ bilgilerle iyiden iyiye etekleri tutuşur. Bunu firsat bilen Osmanlı, savaştan önce psikolojik savaşa başlar. Fatih karşı hatta şenlikler başlatır, sesi ürpertici olan borular öttürür, her yanda cayır cayır yanan ateşler yükselir, mehterler çaldırılır. Osmanlı'nın bu durumunu gören Bizans askerleri fikren mağlubiyeti kabullenmeye başlar. Osmanlı tarafında her şeyin iyiye işaret olduğunu anlatan romanlar, Bizans'ta da her şeyin kötüye işaret ettiğini aktarırlar. Meryem Ana'nın tasviri kırılmış, şehre sis çökmüş, eşi görülmedik firtınalar çıkmış, Ayasofya üzerinde sarı 1şık görünmüş ve kaybolmuş, ay tutulması vuku bulmuş, kötü kehanetler hızlıca yayılmaya başlamıştır. Tüm bu felaket haberlerinin aksine, imparator Konstantin, her şeye rağmen vatansever bir yönetici olarak romanlarda işlenmiştir.

Romanların genelinde, Bizans'taki Venedikliler ve Cenevizliler olumsuz tavırdadır. Bu milletler fırsatçı, güvenilmez, güçlünün yanında yer alan milletler olarak tasvir edilmişlerdir. Sadece birkaç romanda Cenevizliler savaş esnasında Bizanslılara sadık kalmışlardır. Bizans Ayasofya'yı toprakları içinde barındırdığından, Hristiyan dünyasının mezhep ayrılıkları bağlamında sıkıntı çektiğine işaret edilir. Kısacası Osmanlı ile karşı karşıya bir de dinden kaynaklanan çatışmalarla mücadele edilmiştir. İncelenen romanlarda, Bizans'ın din birliği olan milletlerle ilişkileri aşağı yukarı aynı bilgiler üzerinde şekillenir.

"Fetih Sırasında Olup Biten Hadiseler" incelenen tüm romanlarda benzer şekilde ifade edilir. Bizans'ın savunmada kullandığı Rum ateşi adlı silahın detayları tüm romanlarda, ifade farklılıkları olsa da aynıdır. Savaşın seyrini değiştirebilecek kadar güçlü olan bu silahın üstesinden Fatih'in mühendislik zekâsı gelir. Diğer bir hadise, Baltaoğlu Süleyman'ın denizden aldığı darbedir. Fatih denizler açısından durumun pek iç açıcı olmadığını bilmesine rağmen alınan mağlubiyetle tüm romanlar Baltaoğlu'nun cezalandırıldığının üstünde durur. Bu olaylara ek olarak, 1453 denilince akla ilk gelen hadise olan, gemilerin karadan yürütülmesi, tüm romanların israrla temas ettiği noktalardan biridir. Değirmenci'nin incelediği 53 romandan sadece Kara Davut romanı bu olaya olumsuz yaklaşır, diğer tüm romanlar övgüyle bahseder. Fethin gerçekleşmesine ramak kala Fatih centilmen ve şeriat kurallarına uygun bir harekette bulunarak Bizans'a son kez elçi gönderir. Romanlardan tespit edildiği kadarıyla, son elçi gönderilmesi tarihle ilişkilidir. Fatih fethin gerçekleşmesine birkaç gün kala psikolojik baskıyı iyice artırarak askerlere şenlikler düzenlenir ve şehrin ganimeti vaat edilir. Günlerdir devam eden gürültüler, davul ve zil sesleri fetihten bir gece evvel durdurulur ve tabiri caizse, firtına öncesi sessizlik yaşanır. Böylece Bizans, olacakların tamamen farkına varmıştır.

Romanlar fetih esnasına oldukça detaylı değinir. Önemli hususlardan olan "Papazların Müslüman Olup Din Değiștirmesi” Fatih Sultan Mehmet, Bizansll 
Beyaz Güvercin romanları bağlamında irdelenir. Fetih, 29 Mayıs 1453'te gerçekleşir ve zikredilen tüm romanlar bu tarihe riayet eder. Fatih'in beyaz at üzerinde şehre girmesi, romanlarda çeşitli şekillerde tasvir edilir. Fethe olumlu yaklaşan romanlar, Fatih'in İstanbul'a girmesiyle beraber, yerli halka hoşgörülü ve merhametli yaklaștığının altını çizer. Tarihi bir gerçek olarak da karșımıza çıkan, fetihten sonraki ilk Cuma namazının eşsiz güzellikte olan Ayasofya'da kılınması yine romanların ortak paydasıdır. Ayasofya cami olduktan sonra, başkentin İstanbul olması, bu şehrin ilim ve sanat merkezi haline getirilmesi, hoşgörüyle iskân politikasının uygulanması, şehrin asayişinin sağlanması, mimari ve peyzaj faaliyetlerinin başlaması, Ortodoks Patriğine onay verilerek OrtodoksHristiyan dünyasının gönlünün kazanılması gibi unsurlar, Fatih'in İstanbul'a ne kadar ehemmiyet verdiğinin birer göstergesi olarak romanlarda çeşitli şekilde işlenir.

Kitabın üçüncü ve son bölümü olan "Fethin Şahıs Kadrosu" başlıkta da açıkça anlaşıldığı üzere, romanlarda fetihte etkin pay sahibi olan şahısların ele alındığı bölümdür. Değirmenci romanlardaki fon karakterleri çıkarır ve sadece tarihi şahsiyetleri detaylandırarak tüm romanlarda ortak olan şahıslar üzerinde durur. Fatihin hayatı, doğumu ve doğumunda gerçekleşen olumlu hadiselerle aktarılır. Romanlara göre ta doğumla başlayan serüvenin sonunda, Fatih'in iyi işler yapacağına işaret edilir. İncelenmiş Fatih İstanbul Kapılarında, Ebem Kuşağı (1980) ve Sabır (1980) romanlarında Fatih'in ailesinden bahsedilir. Diğer aile fertlerine nazaran Sultan Murat'ın adı daha çok geçer ancak detaylandırılmaz. Fatih'in annesi Hüma Hatun, üvey annesi Marya, zikredilen isimlerdendir.

“Çocukluğu ve Eğitimi” bölümünde, romanlardan hareketle Fatih'in çocukluğuna dair pek bilgi yoktur. Romanların özellikle üstünde durduğu konu, eğitimdir. Hemen tüm romanlarda Fatih'in çok iyi bir eğitim aldığından ve özellikle Molla Gürani ile Akşemseddin'den dersler aldığından sıkça bahsedilir. "Özel Hayatı" başlığında, romanlarda rastlandığı kadarıyla Sultan'ın eşlerinden ve cariyelerinden söz edilir. Değirmenci, Cumhuriyet'ten sonraki dönemlere kadar romanlarda Fatih'in aşklarına dair bilgi olmadığını tespit etmiştir. Cumhuriyet sonrası romanlarda durum değişerek romanlar, eşlerden ziyade cariyeleri detaylandırır. Araştırmaya dahil olan romanlarda Fatih azami olarak şehvet düşkünü bir karakter olarak çizilir. Ek olarak Değirmenci'nin incelemesi sırasında eleştirdiği konu, Fatih'in eşcinselliği üzerinedir.

Kara Davut ve Akından Akına (1936) romanlarında Fatih'in, tarihte de adı geçen bazı şahsiyetlerle eşcinsel münasebetlerde bulunduğu ve içoğlancı olduğu yazılır. Değirmenci bu hadiselerin gerçekliğinden ve inandırıcılığından emin olunmayacağını yer yer üslubunu sertleştirerek ifade etmekten geri durmaz. "Tarihi roman yazarının elbette bir tasarruf alanı olduğuna inanmaktaylz. Lakin tarihi belgelere dayalı hiçbir delil olmadan, tarihi roman yazarının, tarih $\hat{\imath}$ hadiseleri alt üst etmek gibi bir hakkı olmadı̆̆ını, dolayısıla Fatih imajını oluşturan genel kabuller üzerine bir tahribat yapmamasl gerektiğini 
düşünmekteyiz." (Değirmenci 2021: 162) ifadelerini kullanır. Romanlarda Fatih'in ölümüyle ilgili pek bir emareye rastlanmaz. Ancak kitaptan hareketle genel bir görüş ifade edecek olursak, Fatih'in zehirlenerek öldüğü konusunda bir birleşme söz konusudur.

Fatih'in "D1ş Görünüşü" konusunda doğumundan fetih sonrasına kadar odaklanılan nokta, "kartal" yahut "şahin" gibi delici ve etkileyici bakışlarıdır. Konu edinen tüm romanlar bakışlar konusunda bir hava yaratarak mutabakat sağlamıştır. Sultan genç yaşına rağmen olgun bir görünüme sahiptir. Sesinin gürlügü de araştırmaya dahil olan birkaç romanda ifade edilir. Fatih genel olarak giyimine dikkat eden, gösterişli kıyafetler ile arz-1 endam eden bir sultan olarak çizilmiştir.

Değirmenci, Fatih'in insani yönünü romanlardan hareketle diğer başlıklar altında oldukça detaylı aktarır. Hâlbuki fetih öncesinde ve sonrasında insani yönlere temas eden birçok husus vardır. Ayrı başlıklar altında uzun uzadıya Fatih'in insani yönünün değerlendirilmesi, kitabı gereksiz teferruatlara boğan zayıf bir yöndür. Özetle Fatih, çoğu romanda adil, barışsever, hoşgörülü, zeki, bilgili, cesaretli hırslı kararlı, merhametli; bazen de zalim olarak alıntılar yardımıyla tanıtılır. Fatih'in romanlarda hoşa giden tarafları detaylı, olumsuz taraflar da göz ardı edilmiş olarak karşımıza çıkar.

"Fethin Arkasındaki Askeri ve Siyasi Kadro'ya gelindiğinde Değirmenci'nin tahlilleri isimler üzerine yoğunlaşır. Bu isimlerden ilki, Fatih'in babası Sultan Murad'ın da sadrazamı olan Çandarlı Halil Paşa'dır. Çandarlı romanların on birinde Osmanlı'yı Bizans'a satan bir hain olarak karşımıza çıkarken beşinde sadık ve geri kalan romanlarda tarafsız olarak anlatılır. Ancak romanların Çandarlı konusunda vardığ 1 birlik, fetih fikrine her zaman olumsuz bir yaklaşım içinde oluşudur. İkinci isim Zağanos Paşa'dır ve Çandarlı ile olan sürtüşmelerine değinilir. Zağanos Paşa incelenen hemen bütün romanlarda fetih yanlısı bir tavır sergiler. Bu yüzden Değirmenci: "Zağanos Paşa, bu yönüyle Sultan Mehmet'in muhabbetini ve güvenini kazanmış bir roman kahramanıdır. Zağanos Paşa bir karşıt güç olarak romanlarda canlılı̆̆ temin ederken, diğer yandan itici bir güç olarak aksiyonu sağlamaktadır." (Değirmenci 2021: 207) belirtir. Dayı Karaca Bey için: "incelediğimiz romanların bazllarında bey, bazılarında bir paşa olarak karşımıza çıkan Dayı Karaca karakteri, daha çok Sultan Mehmet'in özel işleriyle ilgilenen, bazen de fethin altyapısını hazırlayan bazen de elçilik görevlerini üstlenen güvenilir ve kabiliyetli bir devlet adamıdır." (Değirmenci 2021: 211) ifadeleri kullanılır.

Fatih'i eğitimlerinden, fetih motivasyonuna kadar etkileyen isimler "Fethin Arkasındaki İlmi ve Manevi Kadro" başlığında verilir. Adı geçen şahıslar birebir fethin içinde olmasa da fethin fikirsel dinamizmini ve maneviyatı sağlayan şahıslardır. $\mathrm{Bu}$ isimler, Fatih'in hocaları Molla Gürani ve Akşemseddin başta olmak üzere, Hacı Bektaş-1 Veli, Molla Hüsrev, Cebe Ali, Horoz Dede, Ya Vedud Baba, Molla Zeyrek, Molla Fenari ve Şeyh Garip Sultan'dır. Değirmenci bu 
başlığı yine olması gerektiğinden detaylı aktarsa da romanlar bağlamında düşünüldüğünde gerekli duran bir hassasiyettir. Son olarak, romanların karakterler üzerinde bir bütünlüğe vardığı isimler verilir ki bunlar; fethin gerçekleştiğini resmileştirmek üzere Osmanlı bayrağını surlara diken Ulubatlı Hasan, Bizans ile iş birliği içinde bir hain olan Şehzade Orhan, incelenen romanların çoğunluğunda Bizans'ın baş veziri Notaras'ın kızı ve Fatih'in büyük aşkı olarak karşımıza çıkan İren'dir. "Diğer Kahramanlar" başlığı yukarıdaki üç isimle sınırlı olup, kitapta yer alan son alt başliktır. Yazar bu noktadan sonra "Sonuç"lara ve son olarak "Tablo"ya yer vererek kitabı sonlandırır.

Genel itibarı ile bakıldığında, söz konusu çalışma akademik anlamda başarılıdır. Kitap sadece başlığıyla bile okuyucuyu kendine çekebilecek, içerik yönünden oldukça zengin bir araştırmadır. Kitabın güçlü yanları, zayıf yanlarına baskın gelmektedir. Tarihten alınan İstanbul'un fethi malzemesinin romanlarda ne derecede kullanıldığını tespit eden yazar, fethin ana hatlarını, tarihsel roman bağlamında incelemiştir. Kitap tarihî roman türü ile ilgilenen tüm araştırmacıların yap1, malzeme kullanımı, dil kullanımı, anlatım yönü konusunda faydalanabileceği bir çalışma olarak dikkat çekmektedir.

\section{Kaynakça}

DEĞİRMENCİ, Hakan (2021). Türk Romanında Fetih ve Fatih. Ankara: Akçağ Yayınları. 